\title{
No coração da sala de aula: gênero e trabalho docente nas séries iniciais ${ }^{*}$
}

\author{
Érica Renata de Souza**
}

Se "a etnografia é um projeto marcado pelo gênero", Marilia Pinto de Carvalho mostra a veracidade desta frase através de uma pesquisa centrada numa categoria analítica distinta: o "cuidado". Pesquisando as práticas de "cuidado" entre adultos e crianças no interior da instituição escolar, a autora demonstra como o gênero marca o imaginário que regulamenta as práticas docentes. Nesse sentido, investigando o gênero no magistério, identifica-o como criado e transformado no ambiente de trabalho, num contexto de relações hierárquicas. $\mathrm{O}$ trabalho docente aparece como constitú́do pelo gênero $e$ constituinte do gênero. Segundo Carvalho, a Educação tem sido palco de contrapontos entre masculinidade e feminilidade, razão e emoção, objetividade $e$ subjetividade. E não necessariamente a razão $e$ a objetividade estão articuladas ao masculino enquanto a emoção $e$ a subjetividade estariam associadas ao feminino. Esse palco de confrontos situa todas essas categorias atravessadas tanto por feminilidades, quanto masculinidades. Ao mesmo tempo, contradições de raça e classe combinam-se nas identidades de gênero e se rearranjam para acomodar as tensões.

O "cuidado", apesar de não ganhar legitimidade nas pesquisas acadêmicas, marca uma diferença no trabalho das

* Carvalho, Marília Pinto de. São Paulo, Xamã, 1999.

${ }^{* *}$ Doutoranda em Ciências Sociais, área de Família e Relações de Gênero, Instituto de Filosofia e Ciências Humanas, UNICAMP.

1 Tradução livre de "ethnography is a gendered project". DENZIN, Norman. Interpretive ethnography: ethnographic practices for the 21st century. London, Sage, 1996, p.xiii. 
No coração da sala de aula

professoras primárias. O "cuidado" transita entre o familiar e o escolar, articulando as diferentes esferas, ainda que sempre dentro de uma matriz que atribui o cuidado infantil e a maternidade como inatos às mulheres. Para Carvalho, a "cultura escolar" se encarrega de recriar a "cultura do cuidado" que a socialização familiar incorpora nas mulheres. No caso da escola primária, a feminização difundiu um certo modelo de mulher não somente para o sistema escolar, mas para a sociedade mais ampla. Dessa forma, sugere a autora, as práticas do cuidado, a fim de desvincularem-se das naturalizações, deveriam ser incorporadas como objeto de estudo nos cursos de formação, reconhecidas como parte legítima da prática profissional e como objeto de reflexão e conhecimento sistêmico.

Carvalho demonstra uma preocupação em investigar as marcas da "presença feminina" na escola, marcas relacionadas ao predomínio da emoção e afetividade na visão de mundo e do trabalho docente. Nesse sentido, aponta para a necessidade da incorporação do gênero enquanto objeto e categoria explicativa da pesquisa educacional e da investigação da identidade profissional das mulheres professoras primárias. A diferença entre professores homens e mulheres estaria articulada à hierarquia de gênero, na qual as distintas socializações levariam a mulher a se conformar em seu "papel doméstico", de mãe e dona-de-casa, e as professoras combinariam "referenciais domésticos e profissionais, trazendo para a escola habilidades e saberes do trabalho doméstico e da maternagem", adquiridos na socialização. Entretanto, Carvalho sugere que esse processo não é percebido no cotidiano escolar, onde a feminilidade aparece como um dado desqualificado exterior à cultura escolar e à (re)produção de seus valores e saberes. Diante de tal quadro, a autora toma por referencial uma matriz que engloba a maternagem familiar $e$ o fazer pedagógico, onde a categoria do cuidado ganha lugar central, ao lado das construções sociais sobre a infância e a relação adulto-criança. 
Nos capítulos I e II a autora apresenta um apanhado teórico esclarecedor. Oferece ao leitor um breve histórico sobre o feminismo e o posicionamento de algumas de suas teóricas que aderiram à corrente de pensamento denominada "feminismo da diferença" norte-americano, como Nancy Chodorow e Carol Gilligan. Através de Sherry Ortner, Carvalho discute a universalização dos "papéis sociais" e da "psique feminina" pelo feminismo da diferença, mas atenta para não cair no determinismo biológico, considerando todos os binarismos da modernidade que essa discussão engloba: público/privado, natureza/cultura, homem/mulher... Nesse contexto, à mulher relacional e "cuidadora" estaria reservado o espaço doméstico, ao passo em que homens $e$ mulheres são vistos como individualidades diferenciadas em corpos diferenciados. Apoiando-se em Linda Nicholson, Carvalho sugere o feminismo da diferença como um feminismo da uniformidade, que ignora outras "determinações" sociais como classe social, raça ou idade. Segue sua reflexão apoiando-se nessa crítica de Nicholson e nas teorias de Joan Scott, ambas teóricas feministas do pósestruturalismo que enfatizam a linguagem $e$ os processos de significação das relações de poder. Nesse contexto, introduz a questão da feminização do trabalho docente frente à tendência internacional, identificada no Ocidente desde os anos 70 de aumento do número de professoras, inclusive nos níveis médio e superior de ensino, e se propõe a investigar a mulher professora: o que é ela, como foi construída, como é hoje percebida, "quando, como e porque mulheres professoras são ou se tornam diferentes de homens professores" e como as articulações entre mulher e ensino, mulher e criança foram e são utilizadas nas redes sociais de poder.

A autora sugere que a ocupação de professora tem constituído um dos principais "guetos femininos". Aponta para os trabalhos brasileiros dos anos 80 , voltados para a "composição sexual" do magistério, para a sugestão de que as mulheres articulariam o público e o doméstico no âmbito profissional e que 
No coração da sala de aula

seriam percebidas como segundas mães ou tias dos alunos, enquanto pesquisas internacionais surgiam debatendo gênero no âmbito do trabalho docente. Nos anos 90 surgiram no Brasil trabalhos que se utilizaram do conceito norte-americano de caring, traduzido como desvelo, e trabalhos na educação infantil que identificaram a preparação das mulheres para a maternagem e o trabalho doméstico. Tais trabalhos suscitaram a necessidade de investigação nesse campo a fim de se perceber as conexões da maternagem e do "cuidado" com o cotidiano escolar. Carvalho então resgata a Sociologia do Trabalho para pensar a qualificação das professoras enquanto mulheres trabalhadoras "socializadas" para o (e pelo) trabalho doméstico, "pelo conjunto do trabalho reprodutivo". As habilidades associadas à feminilidade $e$ adquiridas socialmente pelas mulheres são vistas como inatas, não sendo consideradas na classificação hierárquica do processo produtivo. A autora propõe-se a investigar como essas habilidades são e não são percebidas e valorizadas pelas próprias professoras primárias e como os raros homens na mesma profissão lidam com essa "representação social" que associa a educação ao feminino.

No capítulo II, especificamente, Carvalho centra-se na categoria do cuidado apropriada no âmbito escolar. Segundo ela, as práticas do cuidado transitam entre o público e o privado, ou seja, as mulheres têm a demanda de seus "serviços" de cuidado tanto no âmbito doméstico quanto no profissional. O cuidado pode ser lido tanto como "categoria teórica explicativa da divisão social do trabalho", quanto como valor ético; pode ser entendido como superexploração ou como afeto. O conceito, associado à prestação de serviços a outrem, tem origem nos estudos psicológicos (relacionamento e "cuidado" na "personalidade das mulheres"/articulação entre mulheres, feminilidade e "cuidado") $e$ sociológicos (o conceito de "cuidado" ganha um caráter descritivo que abarca os trabalhos relacionais ou centrados nas pessoas,

2 Kegoat, Danièle apud Carvalho, M. No coração da sala de aula... Op. cit., p.46. 
nos quais seriam considerados tanto as tarefas quanto as emoções $e$ relações entre os prestadores e os receptores do cuidado). No entanto, escreve Carvalho, "dificilmente os estudos sociológicos incluem a escola e a educação escolar como trabalho centrado na pessoa, deixando de considerar, portanto, a dimensão relacional do trabalho docente". A autora coloca sob escrutínio as formas de cuidado na relação adulto-criança, a qual costuma ser subsumida no conceito das relações de cuidado entre adultos.

O "cuidado" na escola é apropriado como uma concepção universal da "intuição" e da vivência "femininas" que transcendem as supostas racionalidade e dedução "masculinas". $\mathrm{Na}$ maioria da bibliografia internacional consultada pela autora, o cuidado aparece como ideal ético, isto é, a ética nas mulheres nasceria da experiência do cuidado, essa tendência universal aprendida que leva as mulheres a cuidarem dos membros da mesma espécie. Nesse sentido, a referência primordial é o cuidado materno, impulsionado pelo prazer. Para a autora, esses trabalhos que concebem o cuidado como ideal ético não historicizam nem contextualizam tais práticas num modelo ocidental. Ela, por sua vez, sugere a necessidade da "presença materna" e do cuidado no processo da socialização primária como uma exigência do modelo burguês ocidental de família. As práticas de "cuidado" seriam parte, portanto, das transformações articuladas à modernidade.

A autora historiciza o conceito de infância, a institucionalização da educação, o processo disciplinador do corpo no ocidente e, nesse contexto, o surgimento da figura do professor enquanto adulto responsável pelo ensino. É na virada para o século $\mathrm{XX}$ que a concepção pedagógica centrada no desenvolvimento da criança dotada de personalidade aparece, acompanhada de um movimento de identificação da docência com a feminilidade, já que a escola passa a ser vista como extensão do lar e da família idealizada de classe média. O "cuidado" aparece então na sua dimensão disciplinadora, na família e na escola. Essa disciplina, por sua vez, tem como veículo 
o afeto, responsabilidade reservada às mulheres. Esse modelo de professora que surge exige muito mais afetividade que intelectualidade, num processo de atribuição "ideal" do feminino para a ocupação da docência. Esse processo, aliado ao crescente número de mulheres ocupando a profissão, propiciaram a feminização da docência.

Carvalho sugere hoje no Brasil uma educação híbrida $e$ contraditória: propostas com valores associados à masculinidade eficiência, competitividade, racionalidade, cidadania - que silenciam sobre o cuidado e o afeto, mas exercidas por professoras que mantêm, em sua prática, fortes referências de feminilidade e maternidade - o modelo da segunda mãe profissional. "A mulher realmente tem dois cérebros, um na cabeça e um no útero"3. Segundo a autora, talvez um novo modelo de professora primária esteja surgindo, envolvendo o "cuidado", mas também uma preocupação do aspecto técnico do trabalho, um "padrão feminino" (nos termos de Gilligan) que apresenta uma ênfase na contextualização e na particularidade.

Do capítulo III à Conclusão, a autora se dedica à descrição $e$ análise da sua pesquisa empírica, uma etnografia da sala de aula, realizada numa escola primária pública estadual do município de São Paulo, entre 1996 e 1998, na qual procurou investigar os processos de "socialização" $e$ formação das professoras $e$ suas práticas cotidianas de "cuidado". Carvalho faz um relato minucioso sobre sua trajetória na relação com os atores sociais: as dificuldades para conseguir um lugar na intimidade dos professores, as diversas identificações que recebeu ao longo do processo e a complexa articulação do material empírico com as teorias.

3 Citação de uma professora primária, extraída por Carvalho de AsSUNÇÃO, Maria Madalena S. Magistério primário e cotidiano escolar. Campinas, Autores Associados, 1996. Outra alusão essencialista ao útero seria a concepção da educadora italiana Maria Montessori (referida por Carvalho) sobre a escola enquanto um útero artificial no qual as relações familiares deveriam ser reproduzidas. 
A escola pesquisada poderia ser considerada, segundo ela, como um "cartão de visitas" das escolas públicas estaduais ${ }^{4}$. Os alunos pertenciam a classes sociais heterogêneas, já que esta se localizava num bairro central e privilegiado de São Paulo, mas recebia - nos termos êmicos - os "filhos de zeladores e de empregadas domésticas" dos luxuosos edifícios situados no bairro, nos quais, inclusive, habitavam algumas professoras da escola.

O quadro docente da escola era formado por 12 professores efetivos e uma estagiária. $\mathrm{O}$ perfil majoritário era o da mulher branca de classe média, casada e com filhos, com idade entre 39 a 49 anos. Apenas uma professora provinha de família de baixa renda, era mãe solteira e negra. ${ }^{5} \mathrm{O}$ único professor (homem) era branco, solteiro e morava nas redondezas da escola. Para esses, excepcionalmente, a profissão não se revelou concebida como constituinte das suas identidades. A homogeneidade da classe social do professorado favorecia uma visão homogênea dos alunos "desfavorecidos", refletida numa postura assistencialista que concebia o cuidado não como direito universal, mas como "suplemento" às carências não supridas pelas famílias. As suas famílias ocupavam um lugar primordial na vida dessas mulheres, $e$ a formação cristã e tradicional de suas famílias de origem propiciava-lhes um discurso da naturalização da profissão enquanto "vocação" ou "dom", na qual o "cuidado" era pressuposto. Os únicos professores que não adotavam a filantropia eram os que "percebiam" a diversidade sócio-

\footnotetext{
${ }^{4}$ A sugestão foi da secretaria de ensino, diante do pedido de Carvalho por uma escola que tivesse algum professor (homem), mas a autora sugere que talvez a indicação também tenha sido feita pela boa reputação da escola.

5 A predominância desse perfil da professora branca de classe média, casada e com filhos, assim como a exceção referente a apenas uma professora negra, também foram dados encontrados em minha pesquisa. SouZA, Érica Renata. Questões de Gênero na Infância e na Escola. Dissertação de Mestrado, Campinas, IFCH/UNICAMP, 1999.
} 
econômica dos alunos: a professora negra ${ }^{6}$ e o único professor homem. O comum aos discursos desses professores era a concepção da criança como um todo (cognitivo e não-cognitivo) $e$ práticas que, em maior ou menor grau, articulavam instrução $e$ "cuidado".

O objetivo de Carvalho, acompanhando cada professor através das observações, entrevistas e conversas informais, era o de tentar perceber as concepções de infância presentes nas suas práticas e preocupações pedagógicas, e em que medida sua relação com os alunos era atravessada intencionalmente pelo afeto. A maternidade total (modelo que pressupõe a extensão da maternidade do lar à escola), embora acompanhasse o discurso de todas elas, na prática, foi encontrada em níveis e formas bastante distintas. A feminilidade, a maternidade e as práticas de cuidado se revelararam rearranjadas contextualmente $e$ particularmente por cada professora, não sendo necessariamente diretamente relacionadas ou dependentes. Os dados apresentados pela autora revelam que, num campo tido como "feminino", o professor homem não tinha seu status de gênero ou profissional prejudicados, mas, pelo contrário, gozava de privilégios. A estrutura do sistema tende a reproduzir a feminização inclusive para professores homens, mas essa feminização não necessariamente é lida dentro da área como ameaçadora à sexualidade; pelo contrário, o "cuidado" masculino é ressignificado e benquisto para a prática pedagógica do professor no interior do sistema. Dessa forma, o "cuidado" é uma prática central para o entendimento do gênero que também ganha visibilidades e leituras diferentes quando exercidos por homens ou

6 Se na pesquisa de Carvalho a professora negra era aquela que mais "percebia" as diferenças sociais (no caso, sócio-econômicas), em minha pesquisa [SouZA, E. R. Questões de Gênero na Infância... Op.cit.] a professora negra também parecia ser aquela que mais se preocupava em trabalhar a questáo sócio-econômica com os alunos contra a (auto)discriminação. A questão da raça, por sua vez, era prioridade de outra professora (branca e de classe média), enquanto a questão de gênero parecia não ser objeto de preocupação para nenhuma professora. 
por mulheres. Além disso, o caso da única professora negra ilustra o quanto as questões de raça, classe e a trajetória individual podem reorganizar a matriz da maternidade total e ressignificar o cuidado.

No coração da sala de aula aparece como uma instigante etnografia de gênero na escola. Carvalho tece sua análise utilizando conceitos presentes na produção sobre educação "cultura escolar", "gueto feminino", "socialização" e outros -, mas a autora introduz novas categorias que tornam a leitura de seu trabalho obrigatória a qualquer estudioso das práticas docentes. Ela nos incita a refletir sobre "o cuidado" enquanto uma categoria analítica, sobretudo na educação, mas também em outros campos do saber. Além disso, nos oferece uma etnografia instigante para repensar como as práticas (individuais, familiares, profissionais, sociais) são inevitavelmente inscritas por gênero e por uma rede de outros marcadores sociais que, muitas vezes, passam despercebidos. 